\title{
SIMULTANEOUS ABSORPTION AND ADSORPTION PROCESSES FOR BIOGAS PURIFICATION USING CA(OH)2 SOLUTION AND ACTIVATED CLINOPTILOLITE ZEOLITE/CHITOSAN COMPOSITES
}

\author{
Eny Kusrini ${ }^{1 *}$, Shella Wu ${ }^{1}$, Bambang Heru Susanto ${ }^{1}$, Maya Lukita ${ }^{1}$, Misri Gozan ${ }^{1}$, Muhammad \\ Dicky Hans $^{1}$, Arif Rahman ${ }^{2}$, Volkan Degirmenci ${ }^{3}$, Anwar Usman ${ }^{4}$ \\ ${ }^{1}$ Department of Chemical Engineering, Faculty of Engineering, Universitas Indonesia, Kampus UI- \\ Depok, Depok 16424, Indonesia \\ ${ }^{2}$ Department of Chemistry, Faculty of Mathematics \& Natural Sciences, Universitas Negeri Jakarta, \\ Rawamangun 13220, Indonesia \\ ${ }^{3}$ School of Engineering, The University of Warwick, Coventry CV4 7AL, UK \\ ${ }^{4}$ Department of Chemistry, Faculty of Science, Universiti Brunei Darussalam, Jalan Tungku Link, \\ Gadong BE1410, Negara Brunei Darussalam
}

(Received: August 2019 / Revised: October 2019 / Accepted: November 2019)

\begin{abstract}
This study examined the effects of acid/base activation and chitosan coating on clinoptilolite zeolite as an adsorbent for biogas purification from palm oil mill effluent (POME) using simultaneous absorption-adsorption methods. The effects of chitosan concentration in the clinoptilolite zeolite/chitosan (ZAC) composites were studied to determine the best type of adsorbent for purifying biogas to obtain the highest methane $\left(\mathrm{CH}_{4}\right)$ concentration: the biogas produced from POME via an anaerobic digestion process had a $\mathrm{CH}_{4}$ concentration of $87 \%$ and a carbon dioxide $\left(\mathrm{CO}_{2}\right)$ concentration of $13 \%$. In this study, the $\mathrm{Ca}(\mathrm{OH})_{2}$ solution was used for the absorption process, and the ZAC composite was used as the adsorbent in the adsorption process. To enhance the adsorption efficiency of the adsorbent when purifying biogas, clinoptilolite zeolite (ZA) was activated using strong acid $(\mathrm{HCl})$ and base $(\mathrm{NaOH})$ in various concentrations (ranging from $1-3 \mathrm{M}$ ), calcination at $450^{\circ} \mathrm{C}$ for $2 \mathrm{~h}$, and coating with chitosan concentrations (ranging from $0.25-1 \mathrm{v} / \mathrm{v} \%$ ). The ZA was coated with chitosan to increase its adsorption efficiency, as chitosan contains high levels of amine and hydroxyl groups that interact with $\mathrm{CO}_{2}$ impurities and form carbamic acid, ultimately producing carbamate salt. The composition of biogas before and after treatment was analyzed using gas chromatography. Overall, the final content of the biogas after the purification process with absorption using the $\mathrm{Ca}(\mathrm{OH})_{2}$ solution and adsorption in a fixed-bed column using the ZAC2-0.5 composite was $0.42 \% \mathrm{CO}_{2}$ and $99.58 \%$ $\mathrm{CH}_{4}$. The purified biogas had a very high methane gas content; thus, this study's findings suggest that purified biogas can be used as a clean energy source for wider industrial applications.
\end{abstract}

Keywords: Biogas purification; Chitosan; Clinoptilolite zeolite; Composite; Methane content; Simultaneous absorption-adsorption

\section{INTRODUCTION}

The production and utilization of biogas for green energy in wider industrial applications and cleaner fuels has attracted a great deal of attention for many countries. It is necessary to purify 
raw biogas to enhance its energy content; this is done by removing impurities such as $\mathrm{CO}_{2}, \mathrm{H}_{2} \mathrm{~S}$, and water vapor. This increases the methane purity of the biogas, making it possible to inhibit corrosion when used in pipelines and other instruments such as column reactor and machine. This also has implications for new green energy, reducing the economic losses from maintenance and operational costs for this devices and also pipelines (Bak et al., 2019).

In contrast, enriching biogas has the potential to replace natural gas in future altogether, as biogas can be used in electricity production in co-generation with heat and power (Kadam \& Panwar, 2017). The amount of $\mathrm{CH}_{4}$ is increased and concentrated in enriched biogas to achieve a similar composition and the same standards as a natural gas, allowing it to be used as transportation fuel and in pipeline systems for household use. Biogas can also be converted into a liquid form using cryogenic freezing, chilling the gas to $-80^{\circ} \mathrm{C}$ and then further chilling it to $-162^{\circ} \mathrm{C}$ (Kadam \& Panwar, 2017). This method makes it more economical to compress and transport the biogas over longer distances for further applications.

Huge increases in the price of fossil fuels since 2008 due to the economic crisis have prompted researchers to study methods of upgrading biogas since $19^{\text {th }}$ century (Osman et al., 2019). Enriching biogas involves removing unwanted gases such as $\mathrm{CO}_{2}, \mathrm{H}_{2} \mathrm{~S}$, and water vapor to increase its calorific value and specific heat and minimize its corrosive nature caused by the acidic gases it contains (Leonzio, 2016; Kusrini et al., 2017). Its high $\mathrm{CO}_{2}$ content results in low calorific value, and further purification of the resultant gas to remove $\mathrm{CO}_{2}$ is required. Some methods for purification include pressure swing adsorption, adsorption, and chemical absorption (Ackley et al., 2003; Alonso-Vicario et al., 2010; Leonzio, 2016). Masyhuri et al. (2013) purified biogas using a $\mathrm{Ca}(\mathrm{OH})_{2}$ solution. Kusrini et al. (2018) captured $\mathrm{CO}_{2}$ using graphite waste composites and ceria. In terms of the adsorptive purification of biogas, researchers have used adsorbents containing physisorption, such as activated carbon and zeolite. Chemisorption efforts have utilized iron oxide and iron oxide hydroxide (Bak et al., 2019). The most-used substances for biogas purification are activated carbon and zeolite (Alonso-Vicario et al., 2010; Peluso et al., 2019).

Recently, researchers have reported the results of applying a fixed-bed column for biogas purification using simultaneous absorption and adsorption methods (Kusrini et al., 2016; Kusrini et al., 2017). However, the effects of acid/base treatments and the concentration of chitosancoated clinoptilolite zeolite have not been reported. This paper investigates the effect of chitosan coating and acid/base activation on clinoptilolite zeolite as an adsorbent for the purification of biogas derived from palm oil mill effluent (POME) using absorption-adsorption methods. This study attempted to determine the best acid/base activation and chitosan coating of an adsorbent for biogas purification using absorption and adsorption methods simultaneously. Clinoptilolite zeolite is the most common natural zeolite; its general chemical formula is $(\mathrm{Na}, \mathrm{K}, \mathrm{Ca})_{4} \mathrm{Al}_{6} \mathrm{Si}_{30} \mathrm{O}_{72} \cdot 24 \mathrm{H}_{2} \mathrm{O}$ with an $\mathrm{Si} / \mathrm{Al}$ ratio ranging from $4.0-5.3$ and a high thermal stability of $600-800^{\circ} \mathrm{C}$ (Kowalczyk et al., 2006). The physico-chemical properties of clinoptilolite zeolites can be modified via thermal and chemical treatments (Kowalczyk et al., 2006). This study used biogas produced from POME; it added $10 \%$ cow feces to activate using anaerobic digestion (Kusrini et al., 2016). Anaerobic digestion is the biological process by which microorganisms break down POME in the absence of oxygen. This anaerobic digestion process produced a biogas volume of approximately $28 \mathrm{~m}^{3}$ with a high $\mathrm{CO}_{2}$ content per ton of POME (Harsono et al., 2014). Tetteh et al. (2018) reported using an organic waste source such as cow dung for biogas production. It promotes waste generation and has promising implications for green energy for use in improved economic and environmental applications (Tetteh et al., 2018). 


\section{EXPERIMENTAL DESIGN}

\subsection{Materials}

POME was obtained from three ponds attached to POME processing facilities that belong to the PT. Perkebunan Nusantara VIII Kertajaya factory located in Malimping (Banten, Indonesia). Natural clinoptilolite zeolite sized 1-2 $\mathrm{mm}$ was obtained from Lampung (Indonesia). All the chemicals used in this study were analytical grade and did not undergo further purification.

\subsection{Activation of Clinoptilolite Zeolite using Acid/base Treatments}

Clinoptilolite zeolite was activated using acid/base treatments according to Kusrini et al. (2016). Natural clinoptilolite zeolite $(200 \mathrm{~g})$ was immersed in $400 \mathrm{~mL} \mathrm{HCl}$ solution of $1 \mathrm{M}$ in a 1:2 (zeolite:acid) mass-to-volume ratio; the mixture was stirred for 2 hours. Then, the mixture was filtered and washed with demineralization water to remove any remaining impurities. The acidactivated zeolite was immersed in a $400 \mathrm{~mL} \mathrm{NaOH}$ solution of $1 \mathrm{M}$ in a 1:2 (zeolite:base) massto-volume ratio. The mixture was then filtered and washed in the same manner for acid activation. The acid/base treatments for the activated zeolite were obtained, and the mixture was calcined at $450^{\circ} \mathrm{C}$ for 2 hours. The activated zeolite was kept in an oven at $110^{\circ} \mathrm{C}$ for 3 hours. The clinoptilolite zeolite activated by the acid/base treatment of $1 \mathrm{M}$ was labelled ZA1. The entire aforementioned method was repeated to prepare the zeolite activated by each acid/base treatment for $2 \mathrm{M}$ and $3 \mathrm{M}$; the mixtures were labelled ZA2 and ZA3, respectively.

\subsection{Preparation of Clinoptilolite Zeolite/chitosan Composites}

To observe the effect of chitosan concentrations on the purification of biogas, the ZA2 adsorbent was modified with chitosan $(0.25 ; 0.5$ and $1 \mathrm{v} / \mathrm{v} \%)$. A clinoptilolite ZAC composite was prepared via impregnation. ZA2 (40 g) was added and immersed in a chitosan solution $(0.25 \mathrm{v} / \mathrm{v} \%)$ then stored in an oven at $110^{\circ} \mathrm{C}$ for 3 hours. The ZA2/chitosan $0.25 \%$ composite was obtained and kept for further characterization (labelled ZAC2-0.25). The same method was repeated to prepare of ZAC composites with chitosan (0.5 and $1 \mathrm{v} / \mathrm{v} \%$ ) (labelled ZAC2-0.5 and ZAC2-1, respectively).

\subsection{Preparation of $\mathrm{Ca}(\mathrm{OH})$ Solution}

A total of $5 \mathrm{~g}$ of $\mathrm{CaO}$ powder was added $1 \mathrm{~L}$ of demineralization water and stirred until the $\mathrm{CaO}$ compound was dissolved and the mixture was homogeneous. $\mathrm{A} \mathrm{Ca}(\mathrm{OH})_{2}$ solution of $1.2 \mathrm{~L}$ with $0.089 \mathrm{M}$ was added, and the mixture was placed in the chamber apparatus for the first absorption stage of the $\mathrm{CO}_{2}$ removal from the biogas.

\subsection{Biogas Production}

The biogas production from the POME was done according to Kusrini et al. (2016). The POME and cow feces $(10 \%)$ were mixed, and the mixture's $\mathrm{pH}$ was adjusted to 7 by adding a $\mathrm{Ca}(\mathrm{OH})_{2}$ solution in order to optimize biogas production. A $50 \mathrm{~L}$ tank digester was used for the continuous production of biogas, and the POME/cow feces solution in ratio of 90:10 (v.\%) was periodically added to the inlet. The residue of the bioprocess was removed through an outlet, and the biogas produced from the anaerobic digestion process flowed into the gas reservoir. A manometer was used to monitor the progress of the biogas production.

\subsection{Purification of Biogas by Simultaneous Absorption-Adsorption Methods}

The biogas purification using the aforementioned combination and simultaneous absorptionadsorption methods was done according to the Kusrini et al. (2017). Biogas purification was carried out in the adsorption column with a ratio of length (L)-to-diameter (D) of 18.75:1. The chamber contained the $\mathrm{Ca}(\mathrm{OH})_{2}$ solution in a quantity of $1.2 \mathrm{~L}$ with a concentration of $0.089 \mathrm{M}$, delivered through the pipe bubble using a peristaltic pump with a biogas flow rate of $100 \mathrm{~mL} / \mathrm{min}$; this was used for the absorption stage of purifying the biogas $(2 \mathrm{~L})$. After the absorption process was complete, purification moved to the adsorption stage in a fixed-bed column using each of the 
aforementioned adsorbents. The adsorbent weighed $2.5 \mathrm{~g}$ per $2 \mathrm{~L}$ of biogas, and the flow rate of the adsorption stage was adjusted to $100 \mathrm{~mL} / \mathrm{min}$ (Kusrini et al., 2016).

\subsection{Characterizations}

Biogas produced from POME and cow feces (10\%) was analyzed via gas chromatography (GC Bruker, USA). A thermal conductivity detector (TCD) and dimethyl polysiloxane were used for the column (BR-Q-PLOT type). The length and the internal diameter was $30 \mathrm{~m}$ and $0.53 \mathrm{~mm}$, respectively. Helium was used as the gas carrier.

\subsection{Determination of $\mathrm{H}_{2} \mathrm{~S}$ in Biogas from POME}

A qualitative measurement was carried out to observe whether or not there was $\mathrm{H}_{2} \mathrm{~S}$ gas in the biogas produced from the POME. A lead acetate solution of $0.1 \mathrm{M}$ was used as a qualitative test. The biogas flowed into the lead acetate solution. If $\mathrm{H}_{2} \mathrm{~S}$ gas is present, it produces a black precipitate called $\mathrm{Pb}$ sulfate. No $\mathrm{Pb}$ sulfate was present in the biogas in this study.

\section{RESULTS AND DISCUSSION}

\subsection{Effect of Time Adsorption and Type of Composite for the Removal of $\mathrm{CO}_{2}$ in Biogas Purification}

The effects of acid/base treatments and chitosan coating in biogas purification were investigated. Prior to application, clinoptilolite zeolite was activated via acid/base treatments in order to dispose of adsorbed gases and soluble impurities that could contain $\mathrm{CO}_{2}$ and $\mathrm{H}_{2} \mathrm{~S}$ at the zeolite's active sites (Alonso-Vicario et al., 2010).

The biogas was first passed through the chamber containing the $\mathrm{Ca}(\mathrm{OH})_{2}$ solution. It was then secondly passed into the column filled with each adsorbent dosage of clinoptilolite ZAC composite $(2.5 \mathrm{~g})$. The $\mathrm{Ca}(\mathrm{OH})_{2}$ solution was used in the absorption stage, reacting with the $\mathrm{CO}_{2}$ in the biogas to form $\mathrm{CaCO}_{3}$. If the $\mathrm{CO}_{2}$ gas reacted with the $\mathrm{Ca}(\mathrm{OH})_{2}$ solution, the $\mathrm{CO}_{2}$ content in the biogas decreased and the methane increased.

After the absorption process, ZA1, ZA2, and ZA3, respectively, were used as adsorbents for the removal of any $\mathrm{CO}_{2}$ that did not react with the $\mathrm{Ca}(\mathrm{OH})_{2}$ solution during the absorption process. This experiment was carried out under optimum operating conditions - namely, a biogas flow rate of $100 \mathrm{~mL} / \mathrm{min}$ and an adsorbent dosage of $2.5 \mathrm{~g}$ (Kusrini et al., 2016). Purification time lasted for $20 \mathrm{~min}$; then, the purified biogas was injected into a gas chromatography (GC) instrument every 5 minutes to observe the $\mathrm{CO}_{2}$ and $\mathrm{CH}_{4}$ concentrations in the biogas (see Figure $1)$.

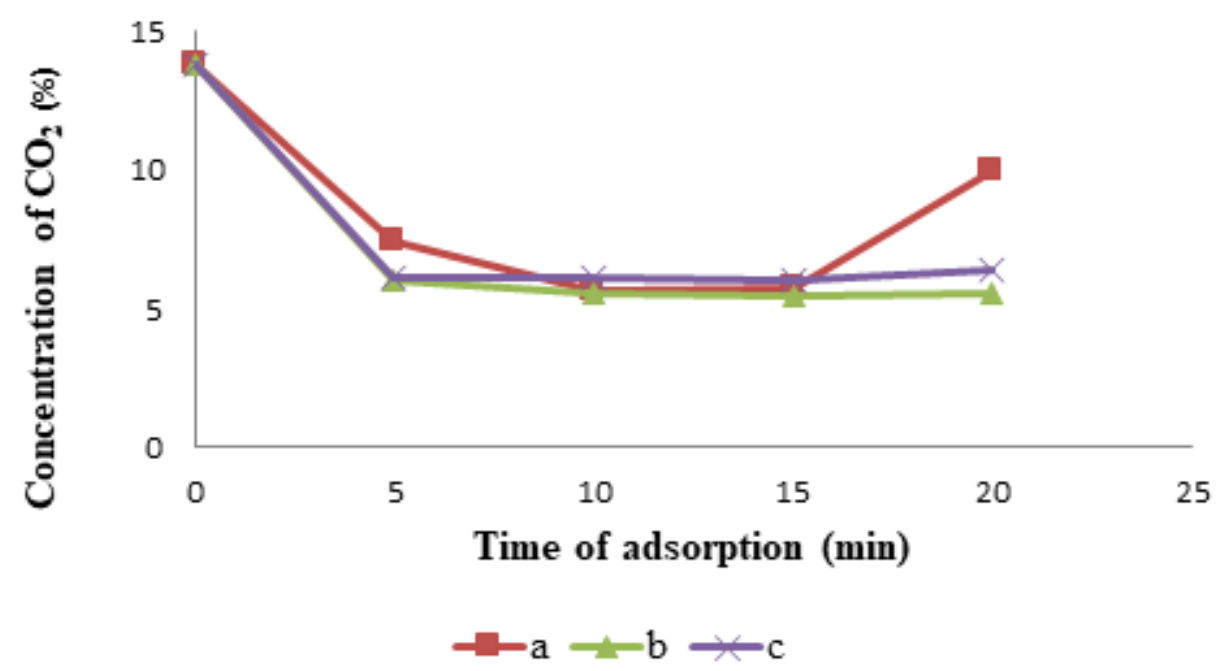

Figure 1 Removal of $\mathrm{CO}_{2}$ at different adsorption times using: (a) ZA1; (b) ZA2; and (c) ZA3 
All of the acid/base activations of the clinoptilolite zeolite showed quite similar levels of $\mathrm{CO}_{2}$ removal from the biogas, except for the ZA1, mainly at minute 20 of time adsorption. Further, $\mathrm{CO}_{2}$ concentration was similar at minutes 10 and 15 of adsorption. The lowest $\mathrm{CO}_{2}$ concentration for ZA1 (9.95\%), ZA2 (5.53\%), and ZA3 (6.37\%) were all at minute 20 of adsorption. Thus, if purified biogas only passes through the absorption stage and does not pass through the adsorption stage, the biogas cannot be absorbed into adsorbent composites because the surface of the activated zeolite is already saturated.

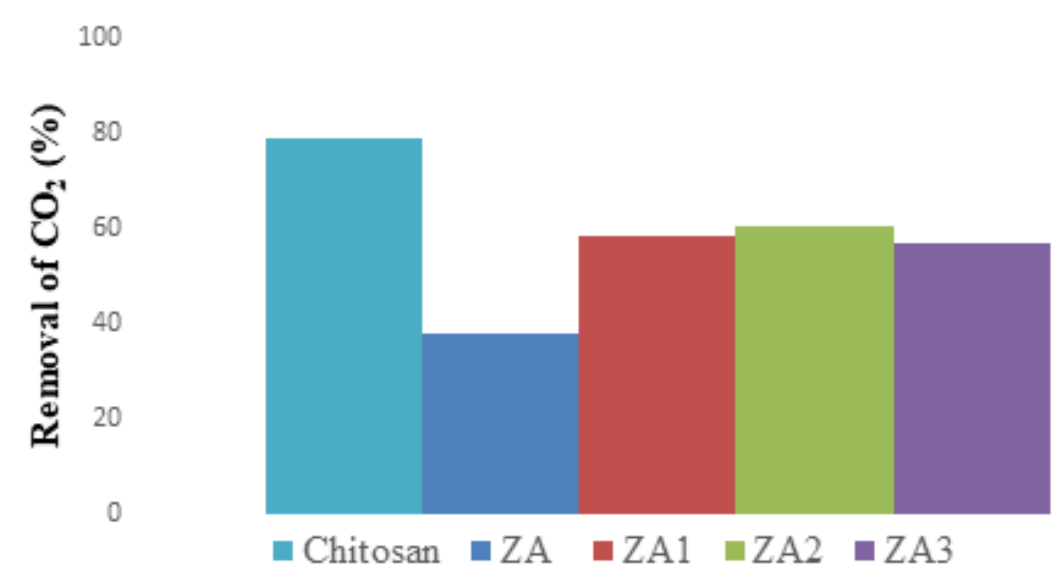

Figure $2 \mathrm{CO}_{2}$ removal using chitosan, ZA, ZA1, ZA2, and ZA3

For the purposes of comparison, clinoptilolite zeolite without treatment (ZA) and chitosan only were also used as adsorbents to purify biogas. They yielded $\mathrm{CO}_{2}$ removal levels of $37.8 \%$ and $78.5 \%$, respectively. As can be seen in Figure 2, the greatest level of $\mathrm{CO}_{2}$ absorption occurred when using ZA2. When ZA was used as the adsorbent, $\mathrm{CO}_{2}$ removal did not reach $50 \%$; therefore, using a strong acid/base on zeolite is appropriate because it can increase the adsorbent's efficiency. In this study, $\mathrm{CO}_{2}$ removal from biogas reached $60.5 \%$ when using ZA2; this decreased when ZA3 was used as the adsorbent (56.7\%). This is because the structure on the surface of the clinoptilolite zeolite, activated by the $3 \mathrm{M}$ acid-base, was damaged. Thus, the pores on the surface of the zeolite were irregular and became ineffective in $\mathrm{CO}_{2}$ adsorption. Thus, to observe the effect of chitosan concentration, the ZA2 adsorbent was modified with chitosan $(0.25$, 0.5 , and $1 \mathrm{v} / \mathrm{v} \%$ ). Here, chitosan was not directly used as an adsorbent for purification because it can be damaged once a temperature of $250^{\circ} \mathrm{C}$ is reached. Further, it is more expensive than naturally occurring zeolite, making it more economical to use natural zeolite that is coated with chitosan to increase its adsorption capacity.

\subsection{The Effect of Chitosan Concentrations as an Adsorbent on ZAC2 Composites}

The previous biogas purification results revealed that ZA2 yielded greater removal of $\mathrm{CO}_{2}$ compared to other variations. Therefore, to determine the optimal chitosan concentration for biogas purification, chitosan was used to modify ZA2 $(0.25,0.5$, and $1 \mathrm{v} / \mathrm{v} \%)$. The modification of activated zeolite using chitosan increases the adsorption efficiency of natural zeolite because the amine groups of chitosan can react to and bind with $\mathrm{CO}_{2}$ to form carbamic acid, which in turn reacts with other amines to form carbamate salt.

As can be seen in Figure 3, coating the clinoptilolite zeolite surface with chitosan can increase its adsorption efficiency in removing $\mathrm{CO}_{2}$. This may due to the Van der Waals interaction between the activated zeolite with the acid/base treatment, allowing the $\mathrm{CO}_{2}$ in the biogas to react with the amine group of the chitosan, increasing $\mathrm{CO}_{2}$ absorption and adsorption. Here, $\mathrm{CO}_{2}$ removal only reached $60.45 \%$ when ZA2 was used, but when ZA2 was coated with chitosan (ZAC2-0.5), removal reached $96.42 \%$; ZAC2-1 removal reached $95.71 \%$ (see Figure 4). Therefore, the best 
adsorbent obtained from this study was ZAC2-0.5 (i.e., the optimal chitosan concentration was only $0.5 \%$ ). The final content of the biogas after the purification process with absorption with the $\mathrm{Ca}(\mathrm{CO})_{2}$ solution and adsorption in a fixed-bed column using the ZAC2-0.5 composite was $0.42 \% \mathrm{CO}_{2}$ and $99.58 \% \mathrm{CH}_{4}$. Comparisons of ZA, chitosan, ZA2, and ZAC2-0.5 are shown in Figure 5. The clinoptilolite zeolite was completely stable throughout the absorption-adsorption process. There is an abundancy of clinoptilolite zeolite in Indonesia, making it, and the adsorption process applied here in which biogas from POME and cow feces $(10 \%)$ was purified using simultaneous absorption-adsorption methods with a $\mathrm{Ca}(\mathrm{OH})_{2}$ solution and ZAC composite, lowcost and highly attractive. This study confirms the importance of selecting the optimal acid/base activation and chitosan coating, which can be responsible for biogas purification and/or $\mathrm{CO}_{2}$ removal from biogas. The results indicate that the purified biogas had a very high methane gas content and gas impurities so small that it can be used as a clean energy source in wider industrial applications.

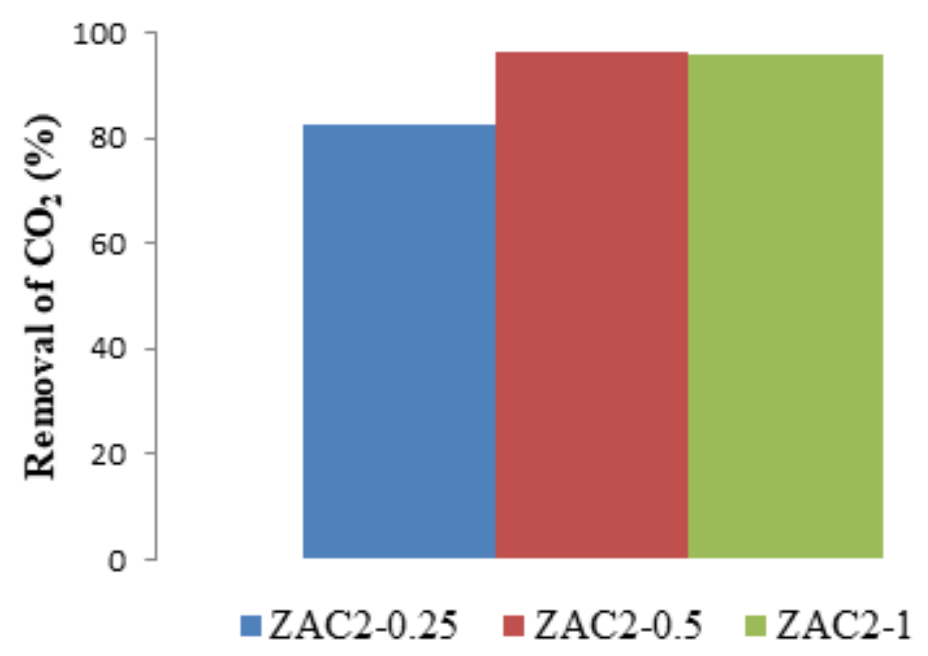

Figure 3 Removal of $\mathrm{CO}_{2}$ using ZAC2-0.25, ZAC2-0.5, and ZAC2-1 composites

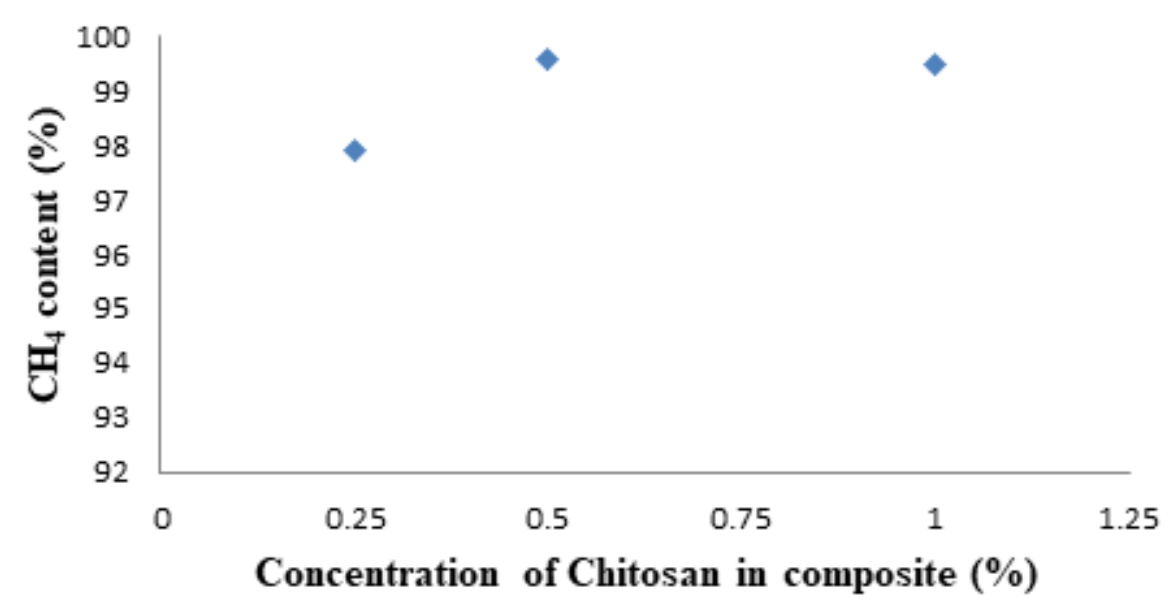

Figure 4 Effect of chitosan concentration in ZA2-0.25, ZAC2-05, and ZAC-1 composites for $\mathrm{CO}_{2}$ removal

Removal of $\mathrm{CO}_{2}$ using chitosan, ZA, ZA2, and ZAC2-0.5 as adsorbents yielded $78.5 \%, 37.9 \%$, $60.5 \%$, and $96.94 \%$, respectively (see Figure 5). The chitosan had a significant effect on $\mathrm{CO}_{2}$ removal because the amine groups bonded with the oxygen atoms of the $\mathrm{CO}_{2}$ and formed a 
carbamic acid, ultimately producing carbamate salt. $\mathrm{CO}_{2}$ removal using the ZAC2-0.5 composite $(96.94 \%)$ was more successful than that used in the simultaneous absorption-adsorption method featuring two columns and a ZAC composite (reaching 83\%) (Kusrini et al., 2017).

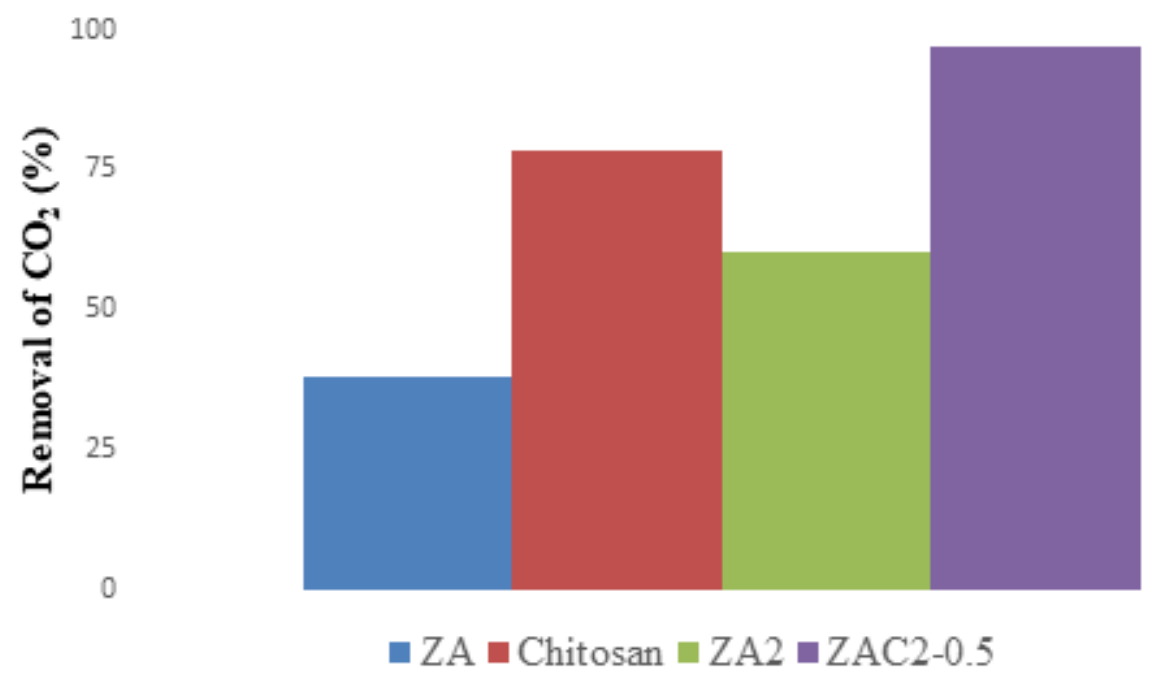

Figure 5 Comparison of adsorbent performance in biogas purification

\section{CONCLUSION}

This study successfully modified clinoptilolite zeolites via acid/base activation, calcination, and coating with chitosan and applied them as an adsorbent to purify biogas from POME using simultaneous absorption and adsorption methods. The modification changed the structure of the clinoptilolite zeolites, making them highly effective as an adsorbent to remove $\mathrm{CO}_{2}$ from biogas. The final content of the biogas after the purification process with absorption with the $\mathrm{Ca}(\mathrm{CO})_{2}$ solution and adsorption in a fixed-bed column using the ZAC2-0.5 composite was the most effective, with a composition of $\mathrm{CH}_{4}(99.58 \%)$ and $\mathrm{CO}_{2}(0.42 \%)$. The resultant purified biogas had a very high methane gas content $(99.58 \%)$ and very low concentration of impurities. This study recommends that biogas produced via purification using a $\mathrm{Ca}(\mathrm{OH})_{2}$ solution and a ZAC0.5 composite be used as a clean energy source for wider industrial applications.

\section{ACKNOWLEDGEMENT}

We thank the Ministry of Agriculture, Republic of Indonesia through Grant of Kerjasama Kemitraan Penelitian dan Pengembangan Pertanian Nasional (KKP3N) No. 54.30/HM.240/I.1/3/2016.

\section{REFERENCES}

Ackley, M.W., Rege, S.U., Himanshu, S., 2003. Application of Natural Zeolites in the Purification and Separation of Gases. Microporous and Mesoporous Materials, Volume 61(1-3), pp. 25-42

Alonso-Vicario, A., Ochoa-Gómez, J.R., Gil-Río, S., Gómez-Jiménez-Aberasturi, O., RamírezLópez, C.A., Torrecilla-Soria, J., Domínguez, A., 2010. Purification and Upgrading of Biogas by Pressure Swing Adsorption on Synthetic and Natural Zeolites. Microporous and Mesoporous Materials, Volume 134(1-3), pp. 100-107

Bak, C.-u, Lim, C.-J., Kim, Y.-D., Kim, W.-S., 2019. Multi-stage Adsorptive Purification Process for Improving Desulfurization Performance of Biogas. Separation and Purification Technology, Volume 227, pp. 1-9 
Harsono, S.S., Grundmann, P., Soebronto, S., 2014. Anaerobic Treatment of Palm Oil Mill Effluents: Potential Contribution to Net Energy Yield and Reduction of Greenhouse Gas Emissions from Biodiesel Production. Journal of Cleaner Production, Volume 64, pp. 619627

Kadam, R., Panwar, N.L., 2017. Recent Advancement in Biogas Enrichment and its Applications. Renewable and Sustainable Energy Reviews, Volume 73, pp. 892-903

Kowalczyk, P., Sprynskyy, M., Terzyk, A.P., Lebedynets, M., Namiesnik, J., Buszewski, B., 2006. Porous Structure of Natural and Modified Clinoptilolites. Journal of Colloid and Interface Science, Volume 297(1), pp. 77-85

Kusrini, E., Lukita, M., Gozan, M., Susanto, B.H., Widodo, T.W., Nasution, D.A., Wu, S., Rahman, A., Siregar, Y.D.I., 2016. Biogas from Palm Oil Mill Effluent: Characterization and Removal of $\mathrm{CO}_{2}$ Using Modified Clinoptilolite Zeolites in a Fixed-bed Column. International Journal of Technology, Volume 7(4), pp. 625-634

Kusrini, E., Lukita, M., Gozan, M., Susanto, B.H., Nasutio, D.A., Rahman, A., Gunawan, C., 2017. Enrichment Process of Biogas using Simultaneous Absorption-Adsorption Methods. In: AIP Conference Proceedings

Kusrini, E., Utami, C.S., Usman, A., Nasruddin., Tito, K.A., 2018. $\mathrm{CO}_{2}$ Capture using Graphite Waste Composites and Ceria. International Journal of Technology, Volume 9(2), pp. 287296

Leonzio, G., 2016. Upgrading of Biogas to Bio-methane with Chemical Absorption Process: Simulation and Environmental Impact. Journal of Cleaner Production, Volume 131, pp. 364-375

Masyhuri, A.P., Ahmad, A.M., Djojowasito, G., 2013. Design of Carbon Dioxide $\left(\mathrm{CO}_{2}\right)$ Absorbent System in Biogas Flow using $\mathrm{Ca}(\mathrm{OH})_{2}$ Solution. Jurnal Keteknikan Pertanian Tropis dan Biosistem, Volume 1, pp. 19-28

Osman, A.I., Abdelkader, A., Farrell, C., Rooney, D., Morgan, K., 2019. Reusing, Recycling and Up-Cycling of Biomass: A Review of Practical and Kinetic Modelling Approaches. Fuel Processing Technology, Volume 192, pp. 179-202

Peluso, A., Gargiulo, N., Aprea, P., Pepe, F., Caputo, D., 2019. Nanoporous Materials as $\mathrm{H}_{2} \mathrm{~S}$ Adsorbents for Biogas Purification: A Review. Separation and Purification Technology, Volume 48, pp. 78-89

Tetteh, E., Amano, K.O.A., Asante-Sackey, D., Armah, E., 2018. Response Surface Optimisation of Biogas Potential in Co-digestion of Miscanthus Fuscus and Cow Dung. International Journal of Technology, Volume 9(5), pp. 944-954 